\title{
Evaluation of Cropping Model of Green Manure Crops with Main Crops for Upland-Specific
}

\author{
Doug Young Chung ${ }^{1 *}$, Misuk Park ${ }^{1}$, Jin-Woong Cho ${ }^{1}$, Sang-Eun Lee ${ }^{2}$, Kwang-Hyun Han $^{3}$, \\ Jin-Hee Ryu', and Seong-Hoon Hyun ${ }^{5}$ \\ ${ }^{1}$ Dept. of Bio-environmental Chem. College of Agriculture and Life Sciences, Chungnam National Univ., Daejeon 305-764, Korea, \\ ${ }^{2}$ Dept. of Plant Resources Sciences, Hankyung National Univ., Ansung 456-749, Korea, ${ }^{3}$ Dept of Environmental and \\ Biological Chem., Chungbuk National Univ., Cheongju 361-763, Korea, ${ }^{4}$ National Institute of Crop Science, RDA, Iksan \\ 570-080, ${ }^{5}$ Div. of Environ. Sci. and Eco. Eng., Col. of Life Sci. and Biotech., Korea Univ. Seoul Korea
}

For organic farming, green manure crops such as leguminous forages and barley have been broadly used to improve soil fertility and soil physical and chemical properties by repeatedly cutting and mulching them directly as winter crop in the field in the rotation. In this investigation we selected 78 agricultural farm corporations as well as individual organic farmhouses related to crop rotation from greenmanure crops to main crops in order to analyze the relationship of cropping system between main crops and green manure crops. The results showed that the green manure crops were divided into two groups as leguminous and nonleguminous crops, representing that those are limited to specific climate and farming systems of regions. Also the 10 or less green manure crops including sudangrass, hairyvetch, italian ryegrass, sorghun, buckwheat, oat, pea, rye, clover, and canola which belong to leguminous crops which are presently cultivated from the organic farmhouses within the rotational crop system. We also confirmed that the major main crops are sweet potato, soybean, corn, tobacco, spinach from usage frequency analyzed by NetMiner H 2.6 which was used to estimate the rotational cropping system among the green manure crops and main crops.

Key words: Green Manure Crops, Main crops, Site-Specific of Upland, Model

\section{Introduction}

지구온난화에 따른 이상 기상이 작물 생육에 영향을 미치 고 있어 파종, 재배 및 수확, 품종선택, 토양보전기술 등 생 산의 안정성을 기본으로 하는 재배기술과 녹비작물을 활용한 토양비옥도 증진과 환경보전을 위한 작부체계가 요구되고 있 다. 녹비작물은 두과와 화본과로 구분하며 자운영, 콩, 헤어 리베치, 팥, 녹두, 클로버 등과 같은 두과는 질소를 식물체 비료로 전환하여 토양에 공급하며 호밀, 보리, 귀리, 들묵새 등 화본과는 두과에 비하여 질소공급량은 작지만 토양 물리 성을 개량하는 효과가 크다 (Lee, 2008; Kim et al., 2008).

작부체계는 토양과 작물의 특징에 따라 작물을 시간과 공간의 조건을 고려하여 농산물을 생산하는 관리체계를 의 미한다. 발에서의 작부체계는 논에 비하며 매우 다양하다. 우리나라의 전통적인 작부체계는 동계작물로 보리와 밀 등 을 재배한 후 여름작물인 벼와 콩을 재배하거나 수수를 혼 작하는 등 각종 작물의 조합으로 비교적 안정된 생산 유지 가 목적이었다. 그러나 최근에는 특정 작물의 집중 재배 시 발생되는 토양병해충에 의한 연작장해 방지와 화학비료 다

\footnotetext{
접수 : 2013. 1. 17 수리 : 2013. 3. 14

*연락저자 : Phone: +82428216739

E-mail: dychung@cnu.ac.kr
}

량 투입에 의한 환경부하를 경감시키고, 토양양분의 불균형 에 의한 각종 생리장해를 경감시키기 위한 방법으로 사용하 고 있다 (Hyun et al., 2010). 한편 유기농업체계에서 합리적 작부체계는 장기적으로 토양비옥도를 유지하고 보전하여 농 산물을 안정적으로 지속하여 생산하는 체계를 의미한다. 이 를 위해 화본과나 두과 계통의 녹비작물을 도입하여 윤작을 실시하면 토양비옥도 유지, 양분의 합리적 관리, 토양환경의 개선, 토양 미생물의 활성 증대 등이 가능하다 (Lee, 2008).

하절기에 주작물을 재배하기 위하여 겨울철 휴한기에 호 밀 및 헤어리베치를 재배하고 다음해 수확한 지상부 생체량 을 조사한 결과 호밀의 경우 3 년 평균 $10 \mathrm{a}$ 당 $2.592 \mathrm{~kg}$ $\left(1.974 \sim 3.700 \mathrm{~kg} \mathrm{laa}^{-1}\right)$ 이었으며 헤어리베치는 3 년간 $10 \mathrm{a}$ 당 평균 $12609 \mathrm{~kg}(1.652 \sim 3803 \mathrm{~kg})$ 수확하였다 (NAAS. 2008). 이는 기온, 토양수분조건 등 환경적인 요인도 있으나 재배종간 차이에 의한 영향으로 판단한다. 그리고 수확된 녹 비작물의 지상부 양분함량은 화본과 녹비작물인 호밀은 헤 어리베치에 비하여 전체적인 양분함량이 낮았으나 탄소함량 은 높은 것으로 조사되었다. 따라서 헤어리베치를 녹비로 시 용할 경우 분해 및 질소무기화 과정이 용이하여 작물이 쉽게 양분을 이용하는 것으로 판단된다 (NAAS, 2008).

녹비작물 도입이 작물생산성에 미치는 효과를 살펴보면 헤어리베치를 윤작한 재배구에서는 관행구와 비교 시 초장, 
경경 및 엽색도에서 유사한 결과를 보인 반면 호밀을 녹비 로 윤작한 재배구에서는 생육이 불량하였다 (NAAS. 2008). 이는 호밀의 탄질비율이 높아 질소기아로 인하여 생육이 불 량하였던 것으로 보고되었다. 따라서 녹비작물을 도입할 때 에는 안정적 생산성을 위하여 양분의 효율적인 관리를 위한 양분수지 분석이 반드시 필요하다.

양분수지는 비료의 사용, 관개수, 강우 및 생물학적 고정 에 의해 투입된 양분과 작물의 흡수, 용탈, 유거, 휘산 및 탈질에 의한 손실된 양분의 차이로 산출한다. 산출된 양분 수지는 양분의 이용효율을 높이고 환경에 미치는 영향을 최 소화하기 위한 근거로 활용할 수 있다. 따라서 유기농업체 계에서 녹비작물을 윤작하여 작물을 재배할 경우 양분의 효 율적인 관리가 가능하다.

따라서 동절기 녹비작물과 하절기 주작물의 윤작재배체 계에서 양분수지와 토양의 이화학성을 개선하기 위한 작물 의 선정 방안이 마련되어야 한다. 따라서 본 연구에서는 녹 비작물과 주작물 간의 상호연관성을 조사하기 위하여 국내 에서 재배되고 있는 작물의 자료를 수립하고 수립된 데이터 베이스를 네트워크분석기법을 활용하여 녹비작물과 주작물 간의 윤작경향을 분석하였다. 또한 네트워크 분석기법을 활 용하여 얻은 결과를 이용하여 전체 작물간 연결성, 중앙 성, 밀도 등으로 계량화하여 토양, 기후, 지역 등의 다양한 요인변화에 알맞은 윤작체계 개발의 근거 자료로 활용할 수 있는 분석도구를 개발하고자 하였다.

\section{Materials and Methods}

주작물과 녹비작물과의 연계성을 고려한 지역별 녹비작 물 이용 현황과 작물의 윤작체계를 조사하여 밭토양 녹비작 물 선발 모형을 설계하기 위하여 문헌조사 및 현장 조사를 실시하였고 조사 결과를 NetMiner II 2.6 (Cyram, Korea)을 이용하여 지역과 지형별 재배현황 네트워크 분석을 실시하 였다.

Data Base 설계 및 작성은 근접 작물 대 일반 작물의 윤 작 가능 여부 (Non-D)와 기여 작물의 특성을 조사하였다. 작물의 특성과 관련한 조사항목은 심근성, 천근성, 질소고 정, 조사료 사용 등이었다. 우리나라에서 주로 이용되는 3 가지 주요 녹비작물인 호밀, 자운영, 헤어리베치의 재배적 특성은 Table 1과 같다.

지역 특성에 맞는 주작물과 녹비작물의 연계성분석을 위 해서 지역별 78 개의 영농조합 및 법인 그리고 유기농가 중 에서 경상북도 지역에 35 개, 전라북도 12 개, 경상남도 9 개, 충청남도에서 1 개의 농가를 대상으로 조사를 실시하였다. 현장 조사를 통해 획득한 자료에 대해서 Cyram 사의 NetMiner II 2.6을 이용하여 네트워크 분석을 실시하였다. 네트워크 분석은 윤작체계, 주요 작물, 녹비작물로 구분하
여 분석을 실시하였다. 네트워크 분석기법은 Netmmer (Ver. 2.6)을 이용하여 결정도 (Degree), 중앙성 분석, 패턴 분석 등의 작물간의 연결 관계 분석과 Spring-KK와 탐색적 분석결과를 시각화를 수행하였다.

\section{Results and Discussion}

지역별로 선정한 영농조합 및 법인 그리고 유기농가를 대상으로 맥류, 서류, 잡곡, 두류, 채소, 특작, 그리고 기타 로 구분하여 지역별 작물의 재배종을 조사하였다 (Table 2). 조사 결과 맥류는 보리를 포함하여 5종, 서류는 감자와 고 구마, 잡곡은 옥수수, 수수 등 6종, 두류는 대두와 녹두 등 6 종, 특작은 대두, 녹두 등 6종 그리고 다양한 종류의 채소 와 기타 작물이 있다.

국내에서 발표된 학술문헌과 본 조사가 실시된 지역 내 에서 재배되고 있는 녹비작물의 종류에 대하여 조사한 결과 현재 녹비작물로 이용되고 있는 작물은 Table 3에서 보는 바와 같이 크게 두과류와 비두과류로 나누어지며 두과 작물 로는 자운영, 헤어리벳치, 알파파 등 14 종이 있으며 비두과 작물로는 수단그라스, 호밀, 이탈리안 라이그래스 등 11종 이 조사되었다.

지대별 작부체계를 살펴보면 남부 평야지대는 벼 후작으 로 밀, 호밀, 귀리 및 이탈리안 라이그라스, 중부 평야지대 에는 총체보리, 호밀 및 밀, 그리고 중북부 및 산간지대에는 밀, 호밀 등을 재배하여 이듬해 모내기 전 총체맥류로 이용 이 가능하다 (Table 4). 또한 겨울철 단백질 사료작물로서 내한성이 강한 두과작물인 헤어리베치를 맥류와 혼파하는 사례도 있었다. 자운영은 재배 특성상 밭토양 보다는 벼 재 배 시 녹비작물로 많이 이용되고 있는데 우리나라에서는 동 계월평균 최저 기온이 $-5^{\circ} \mathrm{C}$ 이상인 지역인 전남 서북부 지 역과 경남 남동부지역에서 적합하며, 동계 월평균 최저 기 온이 $-5^{\circ} \mathrm{C}$ 이하인 지역에서는 월동률이 낮고, 생육정도가 불량하여 자운영 재배에 부적지이다. 헤어리베치는 중북부, 중부 및 남부지역 중에서 옥수수 및 밭작물의 작부 조합 시 유리하고, 과수원의 피복 작물로 가능하다 (Table 3).

Table 3 에서 살펴본 바와 같이 녹비작물은 연평균 기온 에 따라 재배적지가 제한적이었다. 따라서 기후적 조건에 의해 녹비작물의 재배가 제한적인 경기도와 강원도를 대상 으로 조사한 결과 화본과에 속하는 호밀이 빈도 26으로 가 장 많이 재배되고 있는 것으로 조사되었으며 다음으로 콩 (6), 헤어리베치 (4) 순이었다. 그러나 자운영의 경우 경기 도와 강원도 지역에서는 재배가 전혀 없는 것으로 조사되었 다. 한편 용도는 사료와 녹비용이 가장 많았으며 땅콩, 강낭 콩, 팥은 단순 녹비용으로 재배되는 것을 알 수 있었다 (Table 5). 그리고 호밀, 유채, 그리고 자운영은 동절기 재 배작목으로 재배하는 것으로 조사되었다. 
Table 1. Cultivation characteristics of major green manure crops in Korea.

\begin{tabular}{lccc}
\hline \hline \multirow{2}{*}{ Category } & \multicolumn{3}{c}{ Types of Green manure crop } \\
\cline { 2 - 4 } & Rye & Milky-vetch & Hairy-vetch \\
\hline Period of Sowing & after October & September & August to September \\
Nutrient requirement & Nitrogen & Phosphorus, Sulfur & Phosphorus, Sulfur \\
Cold tolerance & Strong, Nationwide & Weak, below Daejeon & Strong, Nationwide \\
Tolerance to moisture & Intermediate & Intermediate & Weak \\
Decomposition rate & Slow & Intermediate & Rapid \\
Effect of green manure & Soil physical property & Microbial status/N supply \\
\hline
\end{tabular}

Table 2. Cultivated crops classified as cropping systems at provinces in Korea.

\begin{tabular}{|c|c|c|c|c|c|c|c|}
\hline Province & Barley & $\begin{array}{l}\text { Tuber } \\
\text { Crop }\end{array}$ & $\begin{array}{l}\text { Miscellaneous } \\
\text { Grain Crop }\end{array}$ & Leguminose & Vegetables & Herbal Crop & Others \\
\hline GG & $\begin{array}{l}\text { Barley } \\
\text { Wheat } \\
\text { Rye } \\
\text { Oats } \\
\text { Triticale }\end{array}$ & $\begin{array}{l}\text { Potato } \\
\text { S w e e t } \\
\text { Potato }\end{array}$ & $\begin{array}{l}\text { Corn } \\
\text { Sorghum } \\
\text { Adlay } \\
\text { Millet }\end{array}$ & $\begin{array}{l}\text { Soybean } \\
\text { Mung Bean } \\
\text { Pea, Cowpea } \\
\text { Kidney Bean, } \\
\text { Adzuki Beans }\end{array}$ & $\begin{array}{l}\text { Lettuce, Chinese Cabbage } \\
\text { Cabbage, Chives, Spinach } \\
\text { A Crown Daisy, Radish, } \\
\text { Pumpkin, Onion, Tomato, } \\
\text { Green Oion Carrot, Strawberry }\end{array}$ & $\begin{array}{l}\text { Flax, } \\
\text { Sesame } \\
\text { Perilla, } \\
\text { Peanut, } \\
\text { Sunflower }\end{array}$ & $\begin{array}{l}\text { Upland Rice } \\
\text { Milky-Vetch } \\
\text { Dahila } \\
\text { Beet } \\
\text { Italian Ryegrass }\end{array}$ \\
\hline GW & $\begin{array}{l}\text { Barley } \\
\text { Wheat } \\
\text { Rye }\end{array}$ & " & $\begin{array}{l}\text { Corn } \\
\text { Sorghum } \\
\text { Miillet } \\
\text { Buckwheat }\end{array}$ & $\begin{array}{l}\text { Soybean } \\
\text { Mung Bean } \\
\text { Adzuki Beans }\end{array}$ & $\begin{array}{l}\text { Radish, Chinese Cabbage } \\
\text { Cabbage, Radish, Pepper, } \\
\text { Cucumber, Carrot }\end{array}$ & $\begin{array}{l}\text { Tobaco, } \\
\text { Sesame } \\
\text { Perilla, } \\
\text { Peanut, } \\
\text { Sunflower, } \\
\text { Angelica }\end{array}$ & $\begin{array}{l}\text { Upland Rice } \\
\text { Ryegrass }\end{array}$ \\
\hline $\mathrm{CB}$ & $\begin{array}{l}\text { Barley } \\
\text { Wheat } \\
\text { Rye } \\
\text { Oats } \\
\text { Triticale }\end{array}$ & " & $\begin{array}{l}\text { Corn } \\
\text { Sorghum } \\
\text { Millet } \\
\text { Buckwheat }\end{array}$ & $\begin{array}{l}\text { Soybean } \\
\text { Mung Bean } \\
\text { Pea, Cowpea } \\
\text { Kidney Bean, } \\
\text { Adzuki Beans }\end{array}$ & $\begin{array}{l}\text { Lettuce, Spinach, Shepherd'S } \\
\text { Purse, Korean Lettuce, White } \\
\text { Radish, Strawberry, Pumpkin, } \\
\text { Garlic, Pepper }\end{array}$ & $\begin{array}{l}\text { Tobaco, } \\
\text { Sesame } \\
\text { Perilla, } \\
\text { canola }\end{array}$ & $\begin{array}{l}\text { Upland Rice } \\
\text { Ryegrass }\end{array}$ \\
\hline $\mathrm{CN}$ & $\begin{array}{l}\text { Barley } \\
\text { Wheat } \\
\text { Rye }\end{array}$ & " & Corn & $\begin{array}{l}\text { Soybean } \\
\text { Mung Bean } \\
\text { Kidney Bean } \\
\text { Adzuki Beans }\end{array}$ & $\begin{array}{l}\text { Chinese Cabbage, Spinach } \\
\text { Strawberry, Pumpkin, } \\
\text { Garlic, Pepper } \\
\text { Radish, Green Onion, Garlic }\end{array}$ & $\begin{array}{l}\text { Tobaco, } \\
\text { Sesame } \\
\text { canola }\end{array}$ & $\begin{array}{l}\text { Upland Rice } \\
\text { Ryegrass }\end{array}$ \\
\hline JB & $\begin{array}{l}\text { Barley } \\
\text { Wheat } \\
\text { Rye }\end{array}$ & " & $\begin{array}{l}\text { Corn } \\
\text { Sorghum } \\
\text { Adlay } \\
\text { Buckwheat }\end{array}$ & $\begin{array}{l}\text { Soybean } \\
\text { Kidney Bean }\end{array}$ & $\begin{array}{l}\text { Lettuce, Chinese Cabbage } \\
\text { Cabbage, Chives, Spinach } \\
\text { A Crown Daisy, White Radish, } \\
\text { Pumpkin, Onion, Tomato, Green } \\
\text { Oion Carrot, Strawberry } \\
\text { Welsh Onion, Garlic, Pepper, } \\
\text { Cucumber, Watermelon, Melon }\end{array}$ & $\begin{array}{l}\text { Flax, } \\
\text { Sesame } \\
\text { Perilla, } \\
\text { Peanut, } \\
\text { Rush, } \\
\text { canola, } \\
\text { Cotton }\end{array}$ & $\begin{array}{l}\text { Beet, } \\
\text { Milky-Vetch } \\
\text { Ryegrass } \\
\text { Italian Ryegrass }\end{array}$ \\
\hline $\mathrm{JN}$ & $\begin{array}{l}\text { Barley } \\
\text { Wheat } \\
\text { Triticale }\end{array}$ & " & $\begin{array}{l}\text { Corn } \\
\text { Buckwheat }\end{array}$ & $\begin{array}{l}\text { Soybean } \\
\text { Kidney Bean }\end{array}$ & $\begin{array}{l}\text { Lettuce, Chives, Spinach } \\
\text { A Crown Daisy, White Radish, } \\
\text { Pumpkin, Onion, Tomato, Green } \\
\text { Oion Carrot, Strawberry } \\
\text { Welsh Onion, Tomato }\end{array}$ & $\begin{array}{l}\text { Flax, Sesame } \\
\text { Perilla, } \\
\text { Peanut, Rush, } \\
\text { canola, Cotton }\end{array}$ & $\begin{array}{l}\text { Alisma } \\
\text { Alpalfa } \\
\text { Ryegrass } \\
\text { Italian Ryegrass }\end{array}$ \\
\hline GB & $\begin{array}{l}\text { Barley } \\
\text { Wheat } \\
\text { Rye } \\
\text { Oats } \\
\text { Triticale }\end{array}$ & $" \prime$ & $\begin{array}{l}\text { Corn } \\
\text { Adlay } \\
\text { Buckwheat }\end{array}$ & $\begin{array}{l}\text { Soybean } \\
\text { Pea } \\
\text { Broad Bean } \\
\text { Kidney Bean }\end{array}$ & $\begin{array}{l}\text { Lettuce, Chives, Spinach,Onion, } \\
\text { Crown Daisy, White Radish, } \\
\text { Pumpkin, Tomato, Green Oion } \\
\text { Carrot, Strawberry, Welsh } \\
\text { Onion, Tomato, Pepper, } \\
\text { Cucumber, Watermelon, Melon } \\
\text { Eggplant, Oriental Melon }\end{array}$ & $\begin{array}{l}\text { Flax, Hemp, } \\
\text { Sesame } \\
\text { Perilla, Rush, } \\
\text { Peanut, } \\
\text { Peppermint, } \\
\text { Crambe, } \\
\text { Safflower }\end{array}$ & $\begin{array}{l}\text { Upland Rice } \\
\text { Milky-Vetch } \\
\text { Orchard Grass } \\
\text { Italian Ryegrass }\end{array}$ \\
\hline GN & $\begin{array}{l}\text { Barley } \\
\text { Wheat }\end{array}$ & " & - & $\begin{array}{l}\text { Soybean } \\
\text { Pea }\end{array}$ & $\begin{array}{l}\text { Garlic, Onion, Melon, Cucumber } \\
\text { Chinese Cabbage, Green Onion, } \\
\text { Watermelon, Strawberry }\end{array}$ & $\begin{array}{l}\text { Flax, Sesame } \\
\text { canola, } \\
\text { Tobaco }\end{array}$ & $\begin{array}{l}\text { Milky-Vetch } \\
\text { Orchard Grass }\end{array}$ \\
\hline $\mathrm{JJ}$ & $\begin{array}{l}\text { Barley } \\
\text { Wheat }\end{array}$ & $" \prime$ & - & Soybean & $\begin{array}{l}\text { Chinese Cabbage, Spinach, } \\
\text { Onion, Radish, Pepper, Pumpkin }\end{array}$ & $\begin{array}{l}\text { Sesame } \\
\text { canola, }\end{array}$ & Upland Rice \\
\hline
\end{tabular}

GG: Gyunggi Province; GW: Gangwon Province; CB:Chungbuk Province; CN: Chungnam Province; JB: Junbuk Province;

JN: Junnam Province; GB: Kyungbuk Province; GN: Kyungnam Province; JJ: Jeju Province 
Table 3. Types of green manure crops cultivated in Korea.

\begin{tabular}{cc}
\hline \hline Leguminous green manure crops & Non-leguminous green manure crops \\
\hline Cowpea, White Clover, Red-Clover, Hairy-Vetch, Milky-Vetch, & Canola, Buckwheat, Millet, Sorghum, Sudangrass, Rye, \\
Oat, Pea, Peanut, Alfalfa, Kidney Bean, Adzuki Beans, & Oat, Ryegrass, Italian Ryegrass \\
Mung Beans, Early Bean, Lupin Etc. & \\
\hline
\end{tabular}

Table 4. Cropping status of green manure crops associated with main crops throughout nation.

\begin{tabular}{|c|c|c|c|}
\hline Green manure crops & Crops before/after & Possible region of cropping system & Remarks \\
\hline \multirow[b]{2}{*}{ Milky-vetch } & \multirow[b]{2}{*}{ Rice } & Nortwest of Jeonnam & $\begin{array}{l}\text { Monthly average temperature greater than }-5^{\circ} \mathrm{C} \\
\text { during winter season }\end{array}$ \\
\hline & & South-eastern of Gyungnam & $\begin{array}{l}\text { Monthly average temperature greater than }-5^{\circ} \mathrm{C} \\
\text { during winter season }\end{array}$ \\
\hline Hairy vetch & $\begin{array}{c}\text { Rice, } \\
\text { Corn, } \\
\text { Sesame, } \\
\text { Orchard } \\
\text { (Cover crop) }\end{array}$ & $\begin{array}{l}\text { North of Middle, } \\
\text { Middle and Southern part }\end{array}$ & $\begin{array}{l}\text { Sowing of Hairy vetch in a rice field with } \\
\text { favorable drainage till the first part of Oct. } \\
\text { Upland field cultivating corn and Sesame } \\
\text { Cover crops of orchard growing gcanola and pear }\end{array}$ \\
\hline
\end{tabular}

Table 5. Characteristics and uses of green manure crops cultivated in provinces of Kyunggi and Kangwon.

\begin{tabular}{lcccc}
\hline \hline Name of crops & Family & Uses & Season/Temperture & Frequency \\
\hline Rye & Gramineae & Forage/Green manure & Winter/Low temp. & 26 \\
Soybean & Legumonosae & Forage & Summer/Low temp. & 6 \\
Hairy vetch & Legumonosae & Forage/Green manure & All/High temp. & 4 \\
Canola & Brassicaceae & Forage/Green manure & Winter/Low temp. & 1 \\
Adzuki beans & Legumonosae & Green manure & Summer/Low temp. & 1 \\
Milky-vetch & Legumonosae & Green manure & Winter/High temp. & 0 \\
\hline
\end{tabular}

Table 6. Top 10 crops selected by cultivation frequency obtained from investigation sites.

\begin{tabular}{lcccc}
\hline \hline Name of Crop & Family & Uses & Character & Frequency \\
\hline Corn & Gramineae & Food & Summer/High temp. & 20 \\
Sesame & Pedaliaceae & Oil & Summer/High temp. & 17 \\
Soybean & Legumonosae & Forage & Summer/Low temp. & 14 \\
Potato & Solanaceae & Food & Summer/Low temp. & 9 \\
Sweet potato & (Meliaceae & Food & Summer & 8 \\
Sorghum & Gramineae & Food & High temp. & 7 \\
Rye & Gramineae & Food/Green manure Forage & Winter/Low temp & 6 \\
Sudangrass & Gramineae & Forage & High temp. & 6 \\
Hairy-vetch & Legumonosae & Green manure/Forage & High temp. & 6 \\
Peanut & Legumonosae & Food/Green manure & Summer/Low temp. & 5 \\
Total & & & 98 \\
\hline
\end{tabular}

주작물과 녹비작물의 재배빈도수를 기준하여 상위 10 개 작목을 조사한 결과 재배빈도가 가장 높은 것은 하계작물로 서 식용인 옥수수 (20)로 조사되었으며 다음으로는 참깨, 콩이 각각 17,14 였다. 녹비작물인 콩과 호밀, 땅콩은 각각 $14,6,5$ 로 조사되었다 (Table 6).

도형 크기에 따라 작물간의 빈도수 정도를 나타내는
NetMiner II를 이용하여 조사된 지역별 작물재배현황과 재 배빈도를 기준하여 주작물과 녹비작물의 연계성을 조사하 였다 (Fig. 1, 2). 녹비 작물별 이용 실태를 분석한 결과 (Fig. 1) Table 5에서 요약한 바와 같이 윤작에 적용되는 주 요 녹비작물은 총 8작목이며 윤작에서 가장 많이 이용되는 녹비작물은 호밀로 총 26 개의 빈도수를 가지고 있는 것으로 


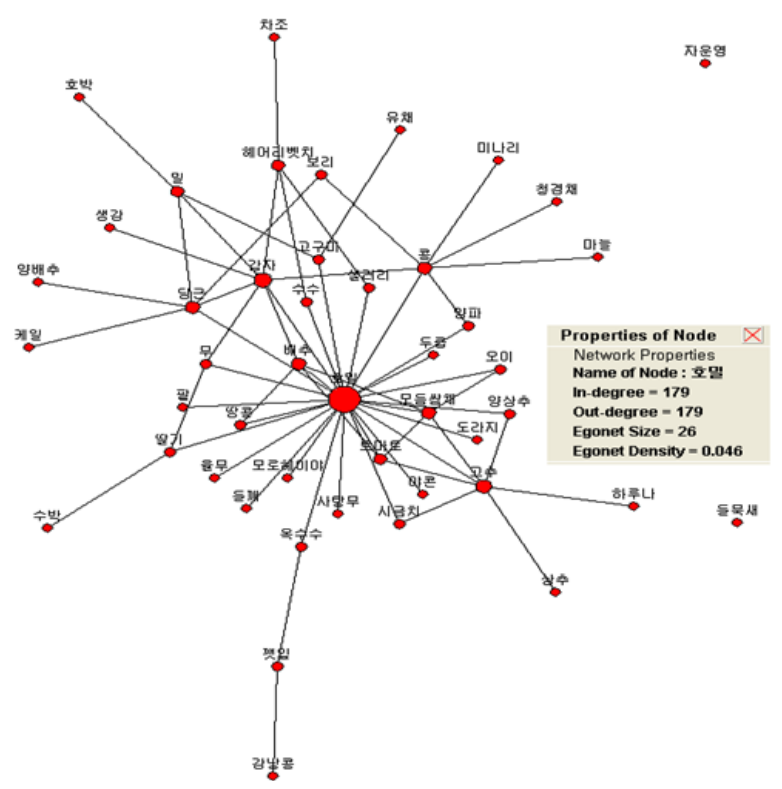

Fig. 1. Green manure crops analyzed by NetMiner II.

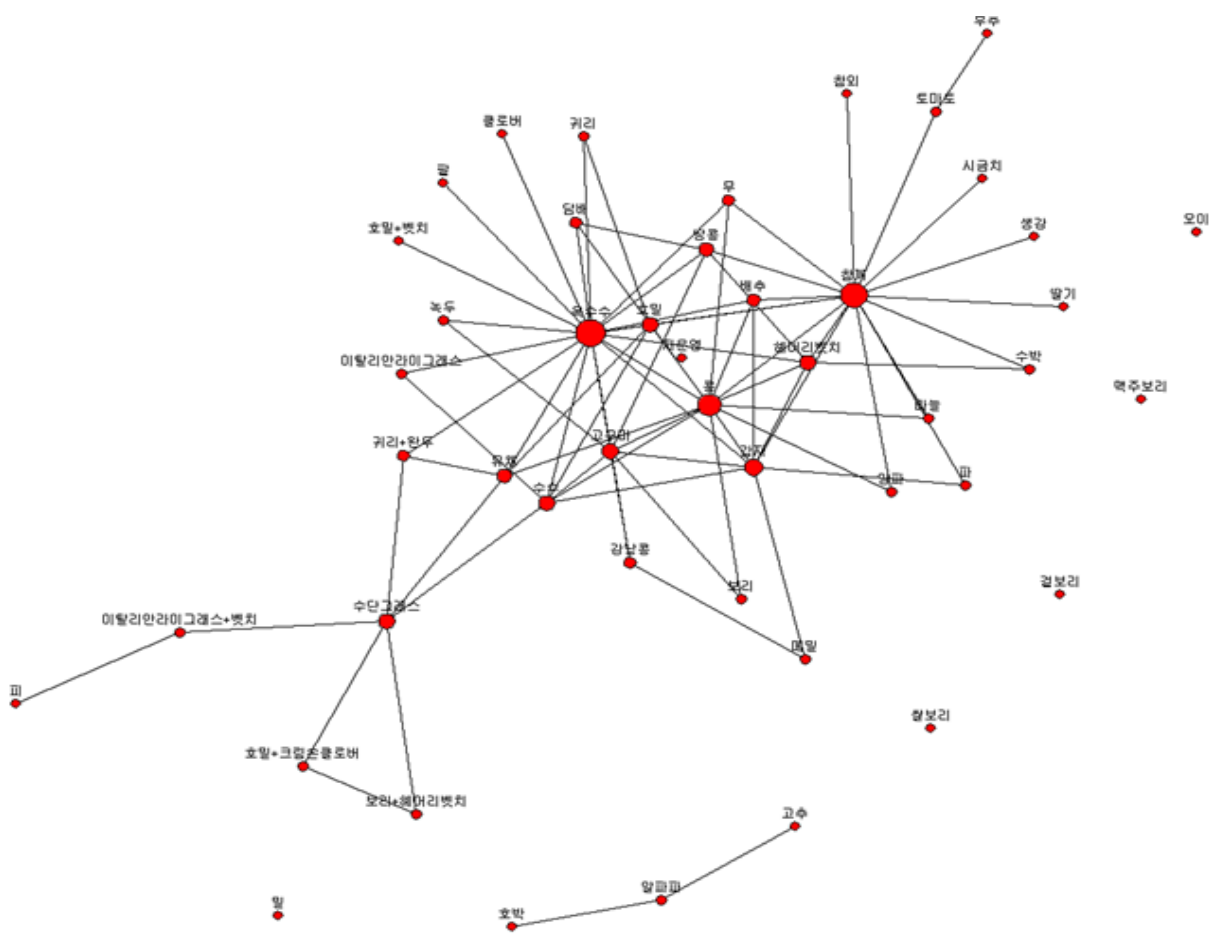

Fig. 2. Crop rotation system analyzed by NetMiner II.

나타났다. 이는 호밀이 윤작에서 녹비작물로써 중심이 되는 위치를 차지하고 있는 것을 의미하고 있다. 호밀을 이어서 콩이 6 개, 헤어리베치가 4 개의 빈도수를 가지고 있는 녹비 작물로 파악이 되었다. 이는 유기농가에서 호밀과 콩, 헤어 리베치를 녹비작물로 많이 재배하는 것으로 생각된다. 반 면, 자운영의 경우 어떠한 빈도수가 없는 것으로 나타나 실 질적으로 유기농가에 있어 윤작을 실시할 경우 많이 이용하 지 않는 것으로 나타났다. 이는 자운영의 재배환경과 관련 이 있는 것으로 판단된다.
윤작체계 분석 결과 고구마, 콩, 옥수수, 담배, 시금치 등 의 빈도수를 기준 시 이와 같은 작물들이 이들이 중점적으 로 재배되고 있다는 것을 알 수 있다 (Fig. 2). 또한 상위 10 개 재배작목인 옥수수, 참깨, 콩 등의 빈도수를 기준 시 옥 수수, 참깨, 콩 등 식량작물과 연계한 윤작체계 녹비작물은 콩, 호밀, 헤어리베치, 땅콩이 연계성이 가장 높은 것으로 조사되었다. 특히, 수단그래스와 같은 사료작물의 경우 빈 도수는 6 을 나타냈으므로 다른 작물들과의 연관성이 높은 것을 알 수 있다. 식량작물 생산 후 사료작물인 수단그래스 
그리고 녹비작물인 콩, 호밀, 땅콩 등으로 이어지는 것을 고 려할 수 있다. 반면, 자운영의 경우는 녹비작물임에도 불구 하고 다른 작물들과의 연결성이 떨어지는 것을 확인할 수 있다. 이는 다른 작물과의 윤작체계에 있어 적합한 윤작체 계 작물이 아님을 알 수 있다.

\section{Conclusion}

생산의 안정성을 기본으로 하는 토양비옥도 증진과 환경 보전을 위한 두과와 화본과로 구분된 녹비작물의 재배기술 을 활용한 작부체계가 요구되고 있다. 지역별 작물의 재배 특성을 조사한 결과 맥류, 서류, 잡곡, 두류는 대두, 특작 등 다양한 종류의 작물과 채소가 재배되고 있었다. 작물과 녹 비작물의 재배빈도수를 기준하여 상위 10 개 작목을 조사한 결과 재배빈도가 가장 높은 것은 하계작물로서 식용 옥수수 (20)로 조사되었으며 다음으로는 참깨, 콩이 각각 17,14 였 다. 녹비작물인 콩과 호밀, 땅콩은 각각 $14,6,5$ 로 조사되었 다. 그리고 녹비작물은 호밀이 윤작에서 녹비작물로써 중심 작물로 이용되고 있으며 자운영은 실질적으로 유기농가에 있어 윤작을 실시할 경우 많이 이용하지 않는 것으로 나타 났다. 따라서, 자운영은 녹비작물임에도 불구하고 윤작체계
에 있어서 윤작체계에 적합한 작물이 아님을 알 수 있다.

\section{Acknowledgement}

This work was carried out with the support of "Cooperative Research Program for Agriculture Science \& Technology Development (Project No. PJ00930201)" Rural Development Administration, Republic of Korea.

\section{References}

NAAS. 2008. Crop productivity with introduction of green manure cops. http://blog.daum.net/niast0158/5474670.

Lee, Y.H. 2008. Organic farming and cropping system. Soil and fertilizer. 33:3-42.

Hyun S.H., Misuk Park, and D.Y. Chung. 2010. Development of crop selection model for site-specific upland with respect to main and rouine crops. KSSSF. Fall Conference. 271.

Kim, P.J., Lee, Y.B., Lee, Y., Yun, H.B. and K.D., Lee, 2008. Evaluation of livestock manure utilization rates as agricultural purpose in developed OECD countries by using nutrient balances, Korean J. Environ. Agri. 27, 337-342. 